\title{
TRAUMATIC PREPATELLAR NEURALGIA
}

\author{
Gavin C. Gordon, Sheffield, England \\ From the Royal Infirmary, Sheffield
}

Persistent investigation of a series of painful knees in which all the accepted methods of investigation were negative revealed a common point of tenderness towards the middle of the outer border of the patella. Careful dissection of the prepatellar [subcutaneous prepatellarbursa in twenty-one such cases led to the definition of a syndrome characterised by the following features: 1) a history of well-remembered violence to the front of the patella, usually in a fall; 2) after the injury, sometimes transient prepatellar swelling, not circumscribed by

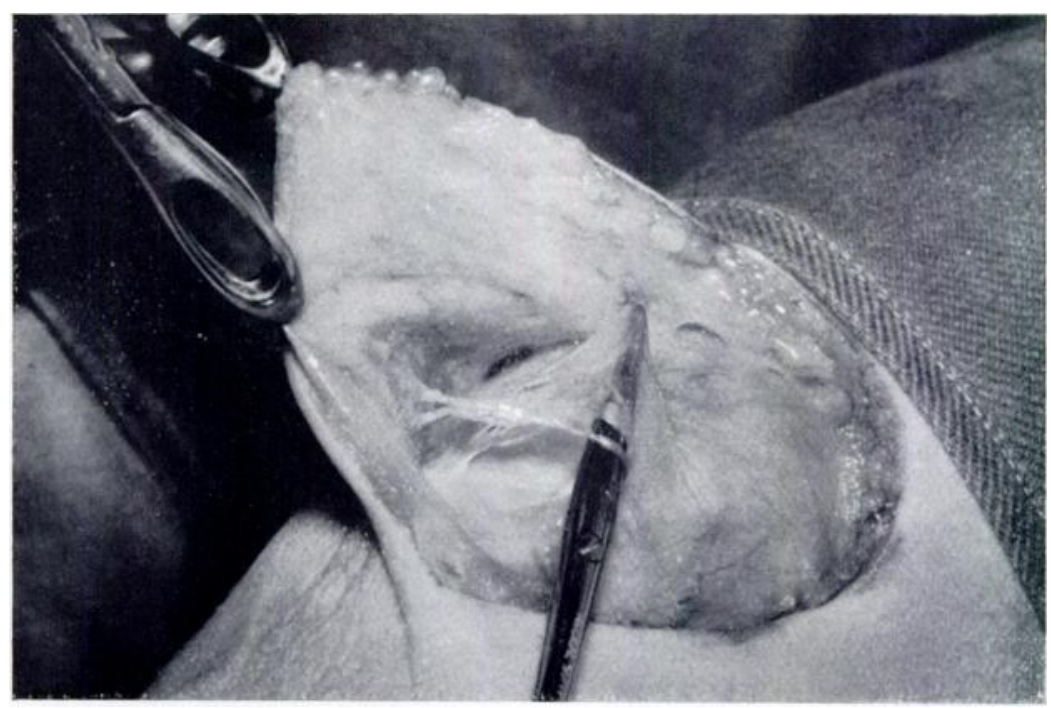

FIG. 1

The neurovascular bundle running from the deep surface of the skin to the bursal wall (supported by forceps).

the bursa; 3) immediately or several weeks after the accident the onset of neuralgic pain deep to the patella, described usually as a dull ache "like toothache"; 4) a precise point of tenderness (of which the patient may have been unaware) towards the middle of the outer border of the patella and nowhere else; 5) persistence of neuralgic pain and disability for many years-up to seven years in this series - with inability to kneel, difficulty in climbing stairs, difficulty in bending the knee and inability to walk far because of increasing ache in the knee; 6) frequent diagnostic difficulty from failure to associate the tenderness with the pain; 7) complete relief on removal of the neurovascular bundle which supplies the prepatellar bursa.

Thomas Walmsley $(\mathbf{1 9 3 4} b)$ gives the best description of the prepatellar bursa. He states: "The subcutaneous tissue over the front of the knee is thin, loose in texture, and nearly devoid of fat. Over the lower part of the patella and the upper part of the patellar ligament it contains a bursa, the largest subcutaneous bursa in the body. Its interior is intersected by fibrous bands which may subdivide it into three parts, namely: 1) a part between the skin and the subcutaneous tissue, 2) a part in the subcutaneous tissue, and 3) a 
part in the lax connective tissue below the thick aponeurotic expansion of the quadriceps femoris which covers the front of the patella and is continued into the patellar ligament." Only the first and second parts are always present.

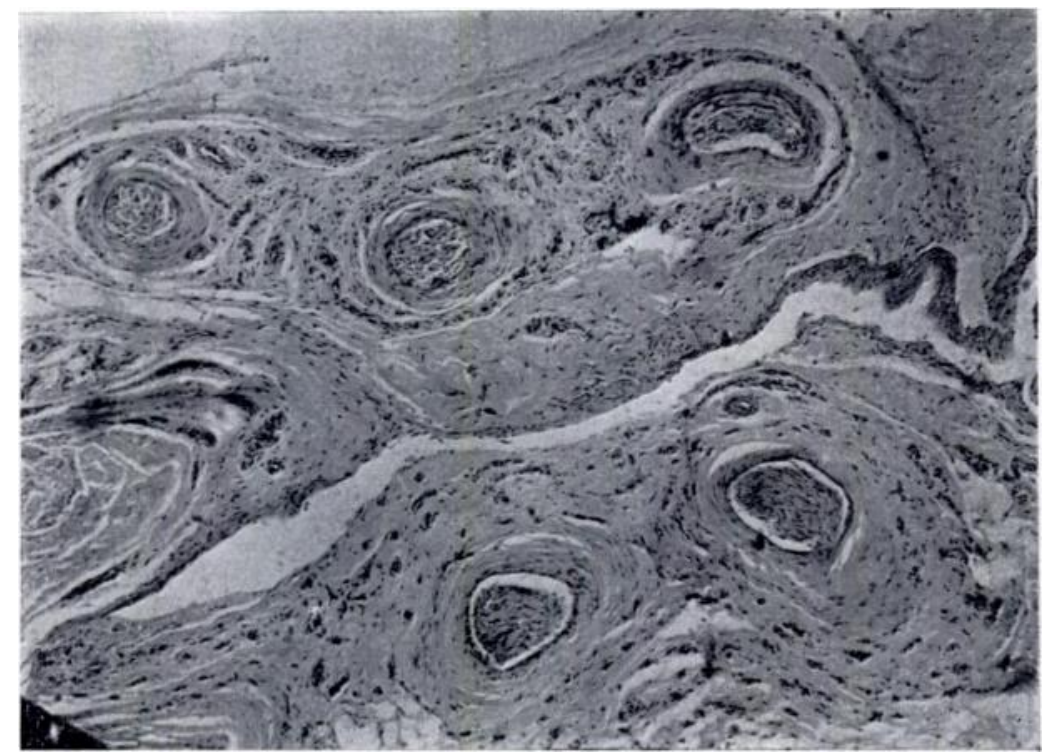

FIG. 2

Section of the neurovascular bundle, with considerable perineural fibrosis.

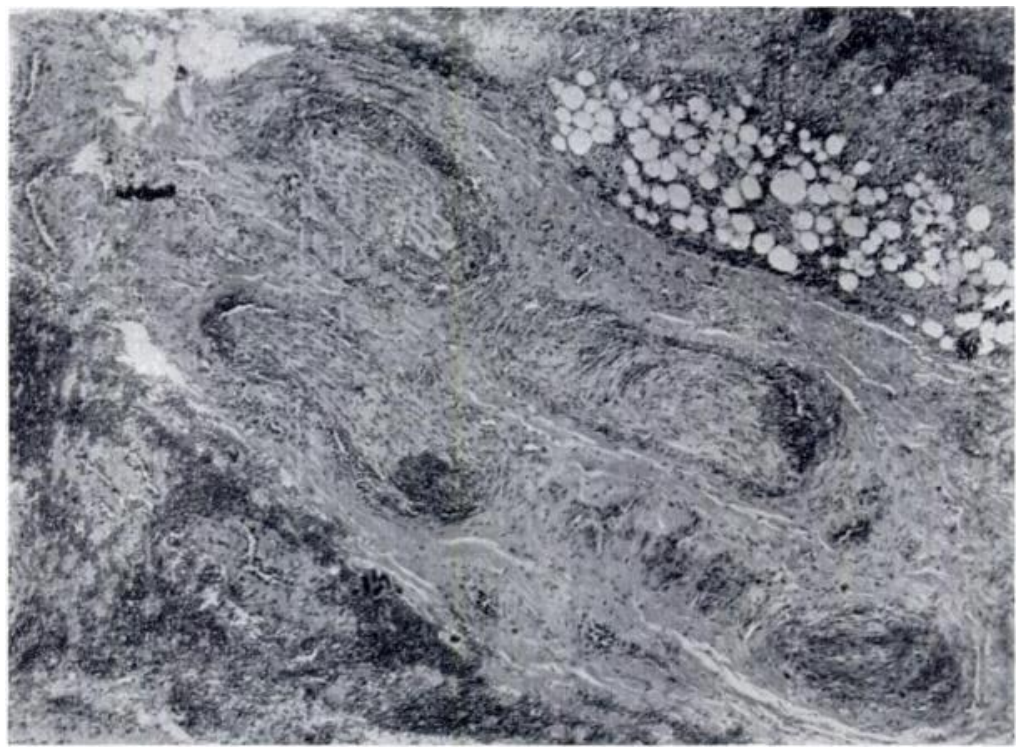

FIG. 3

Section of the neurovascular bundle in the case of strangulated tag, with haemorrhage into the tissue spaces and into the nerves themselves, and with gross perineural fibrosis.

Dissection in the present cases, frequently after a needle had been inserted into the tender point before anaesthesia, showed that there is a constant neurovascular bundle supplying the prepatellar bursa and issuing from the deep surface of the skin about the middle 
of the lateral border of the patella (Fig. 1). There may be a single large contribution which branches over the bursal wall or many small contributions which are much more difficult to identify. After moderate intermittent pressure the subcutaneous part of the bursa may become so closely attached to the deep surface of the skin that it cannot be dissected free. It is in this area or close to it that the neurovascular bundle is found. Its removal, with a small part of the bursal wall, invariably relieved the original pain. Histological examination of the excised tissue, carried out in fifteen instances, revealed vessels and nerves (Fig. 2). The presence of a neurovascular bundle in this area was verified macroscopically and microscopically in two cadavers.

TABLE I

SumMary OF CASES

\begin{tabular}{|c|c|c|c|c|c|c|c|}
\hline $\begin{array}{c}\text { Case } \\
\text { number }\end{array}$ & $\begin{array}{c}\text { Age } \\
\text { (years) }\end{array}$ & Occupation & $\begin{array}{l}\text { Interval between } \\
\text { injury and operation }\end{array}$ & $\begin{array}{c}\text { Date of } \\
\text { operation }\end{array}$ & $\begin{array}{l}\text { Histological } \\
\text { examination }\end{array}$ & $\begin{array}{l}\text { Date of } \\
\text { review }\end{array}$ & $\begin{array}{l}\text { Residual } \\
\text { symptoms }\end{array}$ \\
\hline 1 & 34 & Housewife & 4 months & $31 / 7 / 50$ & Yes & $10 / 2 / 51$ & None \\
\hline 2 & 28 & Kitchen maid & 2 weeks & $10 / 1 / 51$ & Yes & $17 / 3 / 51$ & None \\
\hline 3 & 51 & Cleaner & 9 weeks & $13 / 2 / 50$ & No & $13 / 2 / 51$ & None \\
\hline 4 & 29 & Miner & 5 months & $20 / 3 / 50$ & No & $10 / 2 / 51$ & None \\
\hline 5 & 31 & Miner & 4 months & $15 / 6,50$ & No & $10 / 2 / 51$ & None \\
\hline 6 & 46 & Housewife & 7 years & $22 / 6 / 50$ & Yes & $10 / 2 / 51$ & None \\
\hline 7 & 26 & Paper mill worker & 9 months & $16 / 6 / 50$ & No & $10 / 2 / 51$ & None \\
\hline 8 & 18 & Warehouse assistant & 6 years & $31 / 7 / 50$ & Yes & $10 / 2 ! 51$ & None \\
\hline 9 & 24 & Machinist & 3 months & $17 / 7 / 50$ & No & $23 / 2 / 51$ & None* \\
\hline 10 & 55 & Miner & 8 days & $7 / 9 / 50$ & No & $7 / 2 / 51$ & None \\
\hline 11 & 49 & Miner & 5 weeks & $7 / 9 / 50$ & Yes & $7 / 2 / 51$ & None \\
\hline 12 & 44 & Bakery assistant & 1 month & $16 / 9 / 50$ & Yes & $21 / 3 / 51$ & Nonet \\
\hline 13 & 40 & Housewife & 5 weeks & $11 / 9 / 50$ & Yes & $10 / 2 / 51$ & None* \\
\hline 14 & 43 & Housewife & 4 years & $25 / 10 / 50$ & Yes & $23 / 2 / 51$ & None \\
\hline 15 & 23 & Fitter & 5 weeks & $1 / 11 / 50$ & Yes & $17 / 3 / 51$ & None \\
\hline 16 & 47 & Housewife & 10 months & $15 / 11 / 50$ & Yes & $23 / 2 / 51$ & None \\
\hline 17 & 15 & Packer & 5 weeks & $31 / 11 / 50$ & Yes & $17 / 3 / 51$ & None \\
\hline 18 & 27 & Housewife & 21 years & $15 / 11 / 50$ & Yes & $17 / 3 / 51$ & None \\
\hline 19 & 43 & Housewife & $2 \frac{1}{4}$ years & $31 / 1 / 50$ & Yes & $6 / 3 / 51$ & None* \\
\hline
\end{tabular}

* After injection of local analgesic into hyperaesthetic point in scar. $\dagger$ After excision of hyperaesthetic point in scar.

The bursa may appear normal, or may show one of the following changes: obliteration by fine adhesions, caused by reaction to the injury; some thickening, with alteration of the fine trabeculae into dense fibrous cords traversing the bursa; or aseptic inflammatory changes, no evidence of which can be detected on the surface and which may have been present for some months. No fluid was found in any of the bursae dissected.

Seemingly part or all of the neurovascular supply to the bursa becomes involved in the reactive and healing processes after acute trauma, with consequent perineural fibrosis (Figs. 2 and 3 ) and the typical neuralgia.

vol. 34 B, NO. 1, FEBRUARY 1952 
Details of the nineteen cases of this series are shown in Table I. One case, in which a strangulated tag was found (Fig. 4), and one case of loose bodies, have been excluded from the series. The strangulated tag is a variant of the condition. Prolonged periods of kneeling lead to coarsening of the trabeculae, resulting in strands which may be avascular or contain part of the neurovascular bundle. When trauma involves the vascular type, strangulation occurs, as seen in Figure 4.

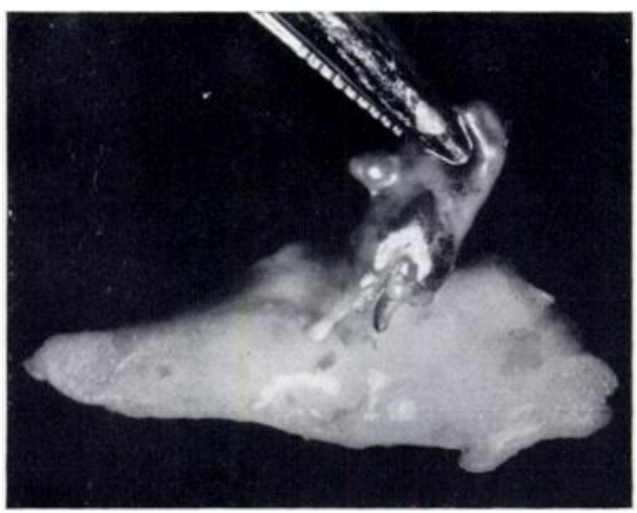

Fig. 4

Photograph showing an intensely congested strangulated tag. Note the fenestration in the bursal wall, from which the neurovascular bundle issues. The small horn seen near the neurovascular bundle was attached in the same way, but broke during manipulation.

Smillie (1946) has described a condition of " neuritis of a branch of the patellar plexus . . assumed to be due to a minor direct injury which produces an irritative lesion of a minute sensory nerve." Apart from the pathology my cases differ from Smillie's in the characteristically constant position of the point of greatest tenderness, the onset of referred neuralgic pain, and the failure to recover spontaneously, in contrast to Smillie's experience that "although the condition may remain for a few weeks, it is self-limiting and will disappear as suddenly as it came."

I wish to acknowledge the constructive criticism and assistance given by $\mathrm{Mr} \mathrm{F}$. W. Holdsworth.

\section{REFERENCES}

Smillie, I. S. (1946): Injuries of the Kinee Joint, p. 288. Edinburgh: E. \& S. Livingstone Ltd.

Walmsley, T. (1934a): The Patellar Plexus. A Manual of Practical Anatomy. Second edition. Part I, p. 252. London: Longmans Green \& Co.

Walmsley, T. (1934b): The Prepatellar Bursa. A Manual of Practical Anatomy. Second edition. l'art I, p. 344. London: Longmans Green \& Co. 